\title{
Developing and delivering a National Framework for Collaborative Police Action to Intimate Partner Violence in Canada
}

\author{
Carmen Gill, ${ }^{*}$ Chief Leanne Fitch ${ }^{\dagger}$
}

\begin{abstract}
The National Framework for Collaborative Police Action to Intimate Partner Violence is a document designed to provide police services across Canada with a guide to leading practices to address intimate partner violence (IPV) and to help police leaders better inform policy development and subsequent police action. The National Framework espouses the importance of a multi-agency, multi-pronged collaborative model designed to keep individuals, families, and communities safe. The document provides a shared language and understanding of IPV that can be used among police agencies and with community partners. The National Framework is the result of collective efforts involving subject matter experts from policing, academia, and community organizations, and was rooted in research funding from the Social Sciences and Humanities Research Council of Canada made available to the Canadian Observatory on the Justice System's Response to Intimate Partner Violence at the University of New Brunswick. In August 2016, the National Framework (NF) was officially endorsed by the Canadian Association of Chiefs of Police.
\end{abstract}

Key Words Intimate partner violence (IPV) police proaction; contemporary community policing; trauma informed lens and response; safety planning; risk management; offender management; evidence-based; Safety and Security Web, think tank; crime prevention and reduction; round tables; Hub and Core; OMES; collaboration; National Framework (NF); shared language.

Journal of CSWB. 2016 Nov; 1(3):51-55

www.journalcswb.ca

\section{INTRODUCTION}

Response and intervention to calls involving intimate partner violence (IPV) is an area of policing that has gained increasing attention over the past three decades and that momentum continues to build rapidly with each reported tragedy in our communities. Additionally, the changing landscape of policing, austerity issues, and social awareness around the issue of IPV, as with other crime, has caused police leaders and governments to reconsider policing priorities and how to pay for rising police costs. A study has shown that approximately 7.4 billion dollars per year was spent in Canada resulting from the impact of spousal violence (Zhang, Hoddenbagh, McDonald, \& Scrim, 2012). In 2013, approximately 336,000 victims of violent crimes reported the incident to the police, including one quarter $(27 \%)$ who were victimized by an intimate partner (Statistics Canada, 2015: 22). Approximately $80 \%$ of all victims of IPV are female (Statistics Canada, 2015: 23). In the same year, police services reported 505 homicides, including 68 intimate partner homicides in
Canada: while the majority of victims (82\%) were female (Statistics Canada, 2014).

Research has demonstrated the importance of understanding the complexity and dynamics at play in IPV situations in order to respond adequately (Eigenberg, Kappler, \& McGuffee, 2012). IPV is a societal issue that necessitates law enforcement response and it is important that police officers view the issue as a violent crime (Logan, Shannon, \& Walker, 2006). Police involvement in cases of IPV has evolved from virtually no response, to a proactive involvement (Buzawa, 2012). It is true that policing in the $21^{\text {st }}$ century is characterized by a proactive and preventative approach to crime and disorder generally and that the "response only model" is no longer an acceptable standard. Contemporary community policing involves collaboration with government, non-government service providers, support groups, stakeholders, and communities taking an active interest in creating and maintaining safe and livable communities. The contemporary notion of a Safety and Security Web (Council of Canadian Academies, 2014) is central to effective and efficient police involvement 
in many complex matters, and the development and delivery of the National Framework for Collaborative Police Action to Intimate Partner Violence is a prime example of this notion in practice. In fact, the Canadian Association of Chiefs of Police (CACP) has recognized that the changing landscape of policing involves an increase in police responsibilities. CACP recognizes more than ever before that the complexity for service delivery cannot be managed by police response alone. Indeed integration, management, and partnerships with other service providers are increasingly important for effective prevention, intervention, and response in the area of IPV. Similar models have emerged across Canada in the form of the Hub and Core efforts in Saskatchewan (McFee \& Taylor, 2014) and Ontario Mobilization \& Engagement Strategy (OMES) (Hawkes, 2016). Likewise, the province New Brunswick created the "Crime Prevention and Reduction Strategy developed in partnership with the Roundtable on Crime and Public Safety and its working groups. The Roundtable brings together community agencies, the police, the private sector, academia, First Nations groups, municipal and federal governments, and several provincial departments to collaborate on improvements to crime prevention policy and practice in the province" (Government of New Brunswick, 2015).

Specifically, the issue of IPV is a priority of Government of New Brunswick, where according to a recent media release:

“... additional activities underway include: provincewide training of all front-line police officers on the issue; the development of a coordinated community approach to intervening with victims and offenders in high risk/ high danger cases of intimate partner violence; the implementation of methods to track files related to this issue throughout the justice system; and studying the merits of introducing intimate partner violence legislation to complement the protections in the Criminal Code and provide further security to victims and families" (Government of New Brunswick, 2015, p. 1).

It is now expected that all professionals intervening in IPV situations will work diligently to provide the best possible service to victims and abusers. Over recent decades we have witnessed the implementation of mandatory arrest/charging policies across Canada, the creation of family violence units in some police agencies, specialized police training, and investigation techniques. We have observed a variety of "best practices" policies, handbooks, and victim services popping up across Canada to better respond to IPV situations. It is recognized policies are important for providing guidance on response to IPV and help to change culture and attitudes toward the issue (Lockwood \& Prohaska, 2015; Gover, Paul, \& Dodge, 2011; DeJong, Burgess-Proctor, \& Elis, 2008).

Our current reality is very different compared to the eras where police officers did not respond, or if they did, they arrived to intervene, calm, and separate the parties and leave the scene thinking everything was alright. Exploring what other community partners and government agencies could offer was not a consideration. While this has changed considerably over the years, what has remained missing in Canada is a consistent "go to" framework of shared language and understanding among police agencies and community partners of specifically what it is we are responding to, and why and how best to go about it.

\section{RATIONALE AND BACKGROUND FOR DEVELOPING A NATIONAL FRAMEWORK}

The intent of the National Framework document is to serve as a foundational guide on which municipal, regional, provincial, and national police organizations can build their own policies. The prevailing principle throughout the National Framework revolves around developing collaborative relationships between police and community partners, which is essential for an effective response to the complex issue of IPV.

The First Step - Collaboration and National Think Tank Keeping in mind the importance of working in partnership to better respond to IPV situations, a group of academics and police officers started a conversation about policies and practices implemented in different regions in Canada. In 2014, a think tank (Gill \& Fitch, 2014) brought together a group of 35 ranking police officers and several academics from across the country to discuss community police response to IPV and sharing practices. Through this process it was agreed that a unified police response to IPV in Canada is critical to moving the agenda forward. While think tank participants understood that the issue of IPV is complex and requires various interventions, they noted the importance of establishing a shared understanding, consistent terminology, and common application of the law across Canada. The results from the think tank were shared with the Canadian Association of Chiefs of Police (CACP) Crime Prevention, Community Safety and Wellbeing Committee, and it was recognized by the Committee that the complexities of IPV requires a multipronged approach including education, prevention, intervention, response, and support. The CACP Committee agreed to adopt the issue and the think tank results as a strategic priority in their collective effort to prevent and reduce harm in Canadian communities. This partnership has proved to be immensely invaluable in legitimizing a collaborative policing and research approach and to support a much needed nudge on the issue of IPV in policing.

\section{The Second Step - Knowledge-Based Working Group and Research}

The second step was to establish a knowledgeable working group to develop a document that would provide police agencies with a foundation for policy development, better intervention, services, and prevention within their regions. In 2015, discussions on the definition and context of IPV, police proaction and intervention in IPV situations and the victims and abusers of IPV further convinced the working group of the importance of establishing a national framework. The framework would be designed to provide consistent language, standards, and policy for Canadian Police Agencies, guide police proaction and intervention on IPV, and identify resources for collaborative education, prevention, intervention, and support for victims, abusers, and communities.

\section{The Third Step - Establishing Legitimacy}

With the support of the Crime Prevention and Community Safety and Wellbeing Committee a CACP committee, an 
article was published in the Canadian Police Chiefs magazine (Gill \& Fitch, 2014) and a resolution was later crafted based on the expert working group's recommendation. The resolution was submitted to the CACP Resolution Committee in the spring of 2015 and was adopted later that same year at the AGM in Quebec City. In the fall 2015, a series of sessions continued with the working group that led to the production of the actual national framework.

The objective of this ongoing work was to provide interim progress reports to the CACP and ensure the completion of a national framework, along with associated steps for putting the framework into action, to the CACP executive board in 2016. The CACP Board of Directors enthusiastically approved the recommendation of the CACP Crime Prevention, Community Safety and Wellbeing Committee to launch the National Framework on Collaborative Police Action on Intimate Partner Violence (IPV) (Figure 1). The National Framework is research- and evidence-based and will be rolled out across Canada as a guide to police leaders and community stakeholders to better inform agency policy development. It will assist policing to provide better service and support to victims and abusers of IPV and create safer communities in doing so. (See the full National IPV Framework Postcard in Appendix A.)

The National Framework, which is available on-line at www.cacp.ca, embraces the very essence of the principles of contemporary community policing and the safety and security web, and highlights the critical importance of collaboration among partners. The principles and practices outlined in the National Framework are intended to reflect current practices. The National Framework is a 'living' document providing content that can be updated accordingly as laws and practices surrounding IPV and evidence-based research evolve.

The following six principles are the pillars of the National Framework:

- Responding to IPV is a shared responsibility across police, public health, and social and community agencies;

- Community safety is promoted through inter-agency collaboration;

- Policies and programs should be evidence-based, and supported by sound and effective research and practices;

- Responses to IPV should acknowledge and mitigate the trauma and other impacts of IPV on victims, offenders, families, responders, and communities;

- Effective case management includes collaboration among service providers to support both victims and offenders by addressing the factors that create risk, in order to prevent further harm; and

- The primary mandate of police is to reduce harm and victimization, and prevent crime.

The National Framework is developed through a traumainformed lens in recognizing and understanding the issue of IPV. A trauma-informed lens refers to the importance of taking into consideration experiences that overwhelm an individual's capacity to overcome difficulties in an intervention. IPV can be a traumatic experience in people's life that can impact their attitudes and behaviour.

The document is divided in three main sections: Definition of IPV; Police Proaction; and Investigation: Guidelines
National framework for collaborative police action on intimate partner violence (IPV)

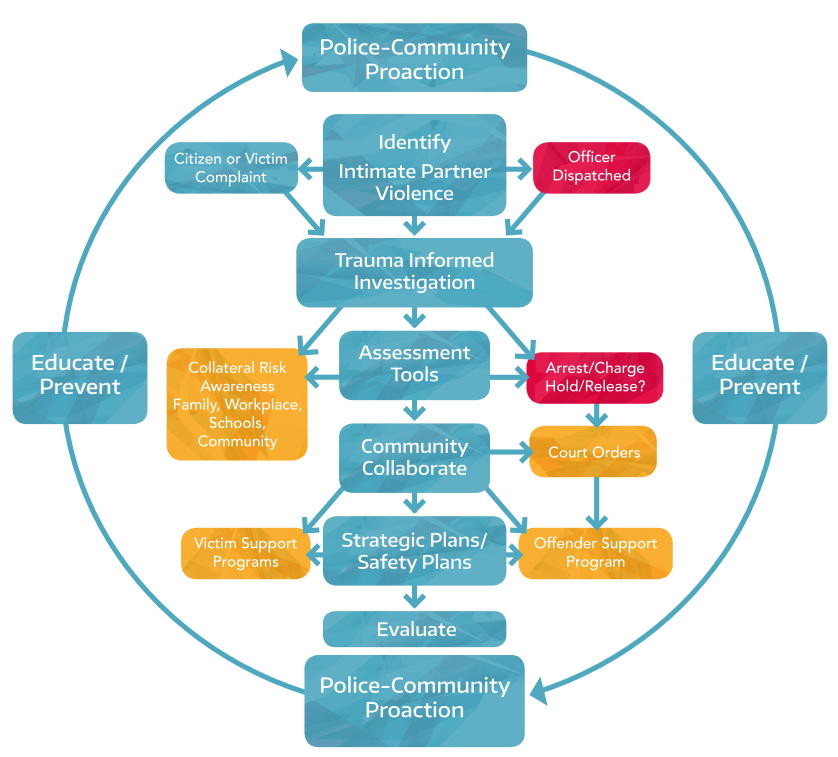

FIGURE 1 Illustrated diagram of the National Framework, along with associated steps for putting the framework into action.

for Canadian Police Services. Two appendices are also included: Managing Victims and Perpetrators of IPV, and Online Resources. The first section addresses the complexity of IPV with definitions and details regarding the severity of the issue and the different impacts it can have on women, men, children, and communities. The second section speaks to the importance of police services being proactive on the issue. Police proaction refers to a preventative, anticipatory approach to policing rather than strictly a reactive response to IPV. It presents an opportunity to prevent future harm and victimization by taking initiatives to improve police intervention. Proaction should be considered for both short- and long-term solutions. The third section lists general investigative practices. Police Services are required to develop and maintain procedures for undertaking and managing investigations into IPV occurrences. This particular section is an adaptation from the Alberta Domestic Violence Handbook (Government of Alberta: 2005).

\section{NEXT STEPS}

The adoption of a National Framework by CACP is the beginning of a series of activities that will be undertaken in the coming months and years. The official launch of the National Framework is planned for November 2016 and it will be followed by the dissemination of the National Framework to all police chiefs in Canada.

The Crime Prevention, Community Safety and Wellbeing Committee continues to recognize the importance of collaborating on many levels to adequately intervene in this issue that is rooted in homes and relationships, acknowledging that safe communities begin with safe, interpersonal, non-violent relationships. The CACP committee remains 
supportive of the continued focus on this topic, and a map to the future is currently underway that will include the following steps:

Ongoing research funding will be pursued with an aim to: 1) gauge the uptake of the National Framework by Canadian Police Agencies 2016-2017 post formal launch; 2) survey to evaluate the use and the impact of the National Framework in agencies and communities across Canada.

- A resource section will be developed that will continue to be monitored to ensure that the appendix material remains current, applicable and accessible;

- Ongoing local, provincial, national, and international presentations will be developed.

- Further grant applications are being prepared to establish a community of practice among police and partners who are dedicated to eradicating intimate partner violence.

- Areas identified for a more intense IPV focus by the CACP Crime Prevention, Community Safety and Wellbeing Committee include barriers to effective response in diverse and unique cultures such as Aboriginal communities, newcomer populations, disabled persons, seniors, LGBTQ, and IPV in police/personal relationships.

\section{ACKNOWLEDGMENTS}

We would like to thank all the people and organizations who have made the framework possible.

\section{CONFLICT OF INTEREST DISCLOSURES}

The authors declare that they have no conflicts of interest.

\section{AUTHOR AFFILIATIONS}

*Department of Sociology, University of New Brunswick, Fredericton, NB; ${ }^{\dagger}$ Fredericton Police Force, Fredericton, NB.

\section{REFERENCES}

Buzawa, E. (2012). The evolving police response to domestic violence. Journal of Police Crisis Negotiations, 12(2), 82-86.

Council of Canadian Academies. (2014). Policing in Canada in the $21^{\text {st }}$ century: New policing for new challenges. The Expert Panel on the Future of Policing Models. Ottawa: Council of Canadian Academies.
Dejong, C., Burgess-Proctor A., \& Elis, L. (2008). Police officer perceptions of intimate partner violence: An analysis of observational data. Violence and Victims, 23(6), 683-696

Eigenberg, H.M., Kappler, V.E., \& McGuffee, K. (2012). Confronting the complexities of domestic violence: A social prescription for rethinking police training. Journal of Police Crisis Negociations, 12(2), 122-145.

Gill, C., Fitch L. (2014, Fall edition). National Think Tank on community police response to intimate partner violence (IPV): Sharing best practices. Canadian Police Chief Magazine,14-16.

Gill, C., Fitch L., \& Greenwood, K. (2016). National framework on collaborative police action on intimate partner violence (IPV). Canadian Observatory on the Justice System's response to Intimate Partner Violence. Fredericton: University of New Brunswick.

Gover, A., Paul, D.P., \& Dodge, M. (2011). Law enforcement officers' attitudes about domestic violence. Violence Against Women, 17(5), 619-636.

Government of Alberta. (2014) Domestic violence handbook for police and crown prosecutors in Alberta. Edmonton: Alberta Justice \& Solicitor General, Government of Alberta.

Government of New Brunswick. (29 October 2015) News Release: Love Shouldn't Hurt - campaign launch. Fredericton: Public Safety and Solicitor General.

Hawkes, J.V.N. (2016). Mobilizing and engaging your community to reduce victimization and reinvest police resources. Journal of Community Safety and Well-Being, 1(2), 21-25.

Lockwood, D., \& Prohaska, A. (2015). Police officer gender and attitudes toward intimate partner violence: How policy can eliminate stereotypes. International Journal of Criminal Justice Sciences, 10(1), 77-89.

Logan, TK., Shannon, L., \& Walker, R. (2006). Police attitudes toward domestic violence offenders. Journal of Interpersonal Violence, 21(10), 1365-1374

McFee, D. R., \& Taylor, N.E. (2014). The Prince Albert Hub and the emergence of collaborative risk-driven community safety. Ottawa: Canadian Police College Discussion Paper Series Vol. 1.

Statistics Canada. (2014). Homicide in Canada, 2013. Ottawa: Canadian Centre for Justice Statistics.

Statistics Canada. (2015) Family violence in Canada: A statistical profile, 2013. Ottawa: Canadian Centre for Justice Statistics.

Zhang, T. Hoddenbagh, J. McDonald, S., \& Scrim, K. (2012) An estimation of the economic impact of spousal violence in Canada, 2009. Ottawa: Department of Justice Canada. 


\section{APPENDICES}

\section{Appendix A: The full National IPV Framework Postcard}

\section{National Framework for \\ Collaborative Police Action on Intimate Partner Violence (IPV)}

The national framework provides police services across Canada with leading practices to address Intimate Partner Violence (IPV) and to better inform policy and collaborative action to keep individuals, families and communities safe.

\section{Statement of Principles}

Responding to IPV is a shared responsibility across police, public health and social and community agencies.

2. Community safety is promoted through inter-agency collaboration

3. Policies and programs should be evidence-based, and supported by sound and effective research and practices.

4. Responses to IPV should acknowledge and mitigate the trauma and other impacts of IPV on victims, offenders, families, responders and communities.

5. Effective case management includes collaboration among service providers to support both victims and offenders by addressing the factors that create risk, in order to prevent further harm.

6. The primary mandate of police is to reduce harm and victimization, and prevent crime.

The United Nations definition of intimate partner violence is adopted in the national framework:

Intimate partner violence refers to behaviour by an intimate partner or ex-partner that causes physical, sexual or psychological harm, including physical aggression, sexual coercion, psychological abuse, and controlling behaviours'

It generally involves a dynamic of power and control from the abuser towards the victim. An intimate relationship is defined as a relationship between opposite-sex or same-sex partners regardless of age whether it is a current and former dating relationships; current and former common-law relationships; current and former married relationships.

1. World Health Organization. (2014). Violence against women. Fact Sheet No. 239.

\section{)UNB}

National framework for collaborative police action on intimate partner violence (IPV)

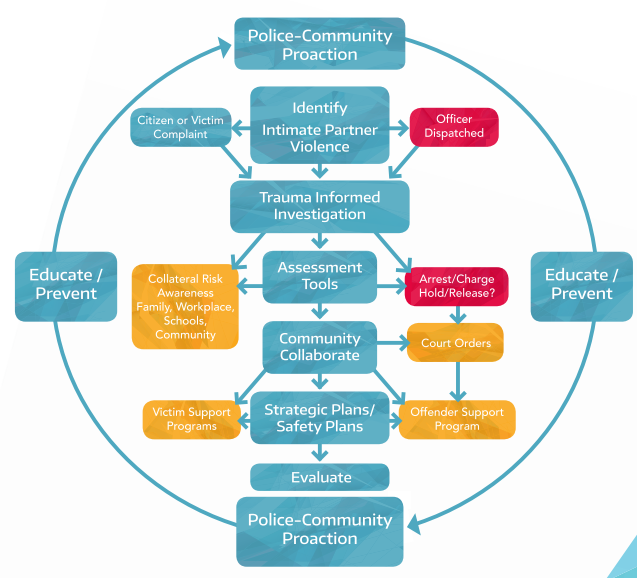

